\title{
Dreams: Where Human Resource Development Is Headed to Deliver Value
}

My psychologist wife has taught me that to understand our past, we can read our journals. To understand our present, we need to look honestly and seriously in a mirror. And to understand our future, we need to examine our dreams. Dream analysis has two parts. One part focuses on our daytime dreams, which symbolize our hopes and aspirations and define where we want to go. For organization leaders, this focus implies having a direction where their organization is headed. The other part of dream analysis examines the subconscious elements of our nighttime dreams. These dreams often deal with the implicit challenges we face and give our mind a way to ponder those challenges and concoct ways to deal with them through our dreams. So by analyzing our nighttime dreams, we can begin to accomplish our daytime visions.

The same logic may be applied to the human resource development (HRD) profession. We can look to our past in textbooks and articles, and we can grasp our present by looking in the mirror of what we do, but we create our future by examining our dreams. These dreams are rooted in the challenges of organizations today and how HRD professionals should respond. They also highlight the hopes and aspirations of HRD professionals. I begin with a brief overview of the current context of business (profit and nonprofit), suggest an overarching vision for the dreams of HRD, report ten challenges that most organizations face, and suggest responses that HRD can make to those challenges.

Note: This editorial is adapted from D. Ulrich and W. Brockbank, The HR Value Proposition (Boston: Harvard Business School Press, 2005), and D. Ulrich and N. Smallwood, "Capitalizing on Capabilities," Harvard Business Review, June 2004, 119-127.

\section{(5) WILEY}




\section{Context}

In conference after conference focused on the world of business and other organizations, similar themes surface. Technology has increased access, accessibility, visibility, and connection. The connected world is smaller, changing rapidly, and has more open information. Customers and clients have become increasingly segmented and persnickety. Investors and donors have become increasingly attuned to and actively concerned about not only financial results but intangibles. Employees represent increasingly diverse demographic backgrounds, including not only race and gender but personal preferences, global or cultural backgrounds, and orientation to work. Competitors come from both traditional large, global players and increasingly smaller innovators. And all of these themes occur in the context of global enterprise, where what happens in one corner of the world can affect organizations throughout the rest of the world.

Most of these trends are outside the control of any one individual or organization and occur in both predictable and unpredictable ways. They affect all aspects of business, from how to fund a firm to how to position the firm in customer minds and how to engineer and deliver products. They also affect the role and responsibility for HRD. HRD's legacy has been to design and deliver training programs for employees inside an organization. With this orientation, HRD professionals have often focused on the tools and techniques of training, being little more than casual observers of trends and not connecting training to those organizational conditions. Now the HRD profession is being asked to connect what they know how to do in order to help their businesses compete better. HRD needs to understand and adapt to these trends.

\section{Vision for HRD's Future}

To respond to changing external realities, HRD professionals should focus their time, energy, and passion on creating value. Value is defined by the receiver more than the giver, so a focus on value means that HRD must identify the receivers of HRD services and prescribe what they receive from insightful HRD work. Employees who attend HRD activities may receive skills and knowledge to do their current and future work better. Line managers and other leaders may use HRD activities to execute strategy by focusing training activities on real organizational issues. They may make training investments to drive results. But HRD work can also be used to connect with targeted customers by designing customer-centric activities and including customers in the training experience. HRD also may help gain credibility with investors by articulating intangible value. As HRD focuses on the creation of value, these four stakeholders become critical to HRD's success. They determine how well HRD practices, professionals, and departments are making wise investments. 


\section{Challenges, Principles, and Practices}

A value focus for HRD raises new challenges and opportunities. The challenges are things that HRD professionals should understand and help manage to create value; the opportunities are the ways that HRD responds to those challenges. Most of the challenges come from research on what is known about how organizations compete in evolving and changing markets and enterprise environments. Following are some of the principles HRD professionals should master, how these principles affect organization capabilities, and what HRD professionals should know and do to turn the principles into practices (see the summary in Table 1).

Challenge 1-Strategic clarity. An organization needs to have a clear and focused point of view about how to succeed in the future. In a business context of technology revolution, globalization, rising consumer demands, new employee expectations, increased competition, and dynamic financial markets, companies have many strategic choices. Some companies have fallen prey to the concept clutter trap. They create visions, missions, principles, strategies, goals, objectives, value statements, and other well-intended documents, but they are plagued with concept clutter and lack strategic clarity. Organizations with strategic clarity have a clear focus on what they are and what they want to accomplish.

Response 1-HRD with a strategic focus. HRD activities from training to coaching to job design should all begin with strategy. Although strategic is not static but evolving, HRD professionals can ensure that the activities they design and deliver institutionalize strategy. This happens when the content of training activities aligns with strategy, coaching focuses on the individual leader's results, and jobs designed to encourage personal development help accomplish strategy. By aligning with strategy, HRD professionals facilitate strategic clarity and help translate strategy into leadership actions and results.

Challenge 2-Speed of change: An organization must learn how to respond to change quickly. It is not hard to see the increasing pace of change in personal and professional lives: laptops become obsolete in eighteen months, emerging markets materialize quickly, the half-life of knowledge is getting shorter, and life in and out of organizations is increasingly intense. In this rapidly changing world, organizations that have the capacity to respond to change can win; those that do not can lose.

Response 2-HRD as a facilitator of change. Responding to change is easier said than done. HRD professionals can play a key role in helping their organizations respond to change. They can see that their programs evolve to be consistent with current and future demands. The cycle time for products that a company sells should reflect the cycle time that HRD programs run. If a 
Table 1. Summary of HRD Challenges and Responses

Challenges Needed for Success
Strategic clarity: Have a clear and focused
point of view about how to win and
compete
Change and speed of change: Anticipate
and respond quickly to changes both
outside and inside the organization
Culture or shared mind-set: Have a firm
brand outside that translates to employee
behaviors and norms inside the company
Leadership and leadership brand: Identify
and create a unique leadership brand by
ensuring the leadership code and crafting
the leadership brand

Learning: Encourage learning among individuals, teams, and the entire organization

Collaboration: Make the whole more than the parts by both efficiency and leverage

Talent: Attract competent individuals for today and tomorrow, and engage those individuals in allocating their discretionary energy to the job

Customer connection: Identify target customers, and work to gain customer share from those target customers

Innovation: Create new ways to do work, develop inventive products, provide unique services, and initiate groundbreaking business models Efficiency: Reduce costs Responses by HRD Professionals

- Facilitate strategic clarity by engaging leaders in options and choices

- Ensure that all HRD activities align with strategy

- Build and enact a disciplined change process

- Assimilate change into a new identity

- Perform a cultural audit

- Make customer reputation real to employees through HRD activities

- Ensure that leaders demonstrate the leadership code

- Prepare a statement of leadership brand, and organize HRD activities around it

- Make continuous learning a priority in all HRD activities

- Generate new ideas by experimenting, acquiring skills, continuous improvement, and benchmarking

- Generalize ideas across boundaries

- Increase efficiency through productivity improvement efforts

- Increase leverage by sharing ideas, people, products, and services

- Build all HRD work on the right talent required for future success by doing a talent audit

- Shape a talent management process that ensures both competence and commitment

- Identify target customers who represent value for the firm

- Find ways to engage those customers in firm activities (for example, participate in training)

- Establish an innovation protocol that helps shape new ideas

- Install a spirit of innovation among all employees

- Increase productivity

- Manage processes efficiently

- Allocate resources on key projects 
company's products need to be updated every eighteen to twenty-four months, the same should be true of HRD programs. They can build change modules into their programs. In the past decade, there have been numerous studies of how to accomplish change successfully. These studies have merged into a set of change disciplines that HRD professionals can teach in their programs. Finally, they can build a mind-set of change. Sustained change is more than a tool kit and checklists of what to do; it requires a mind-set of analyzing, letting go, experimenting, and starting anew. HRD programs can teach both the principles and practices of a change identity among firm employees.

Challenge 3-Culture or shared mind-set: An organization needs to be able to craft a firm brand that has a line of sight into its culture. Gaining a shared mind-set, or firm brand identity, becomes a vital capability. Many firms have moved from individual product brands to firm brands. The Marriott name on a hotel adds value because it gives the traveler confidence in the product. Being affiliated with the Olympics brand is worth millions to companies that want to be associated with the positive image of the Olympics tradition.

Response 3-HRD as the carriers of culture. HR professionals may help identify and shape their shared mind-set, or firm brand, by building a consensus among their management team of what they want the firm to be known for by its best customers in the future. Once a consensus is reached on this identity, they may invest in a series of actions to make the identity real to both customers and employees. This firm brand can then become a central part of all HRD activity. The more it is talked about, acted on, and woven into management processes, the more the firm brand outside becomes the culture inside.

Challenge 4-Leadership brand: A firm needs to be good at embedding leaders throughout the organization who deliver the right results in the right way, that is, who demonstrate a leadership brand. Successful organizations generally have a leadership brand or clear statement of what leaders should know, be, and do. A leadership brand exists when the leaders from top to bottom of an organization have a unique identity. These leaders are identifiable, they are focused, and they possess attributes of success and deliver results. This leadership identity inside is connected to the customer identity outside. Leadership brand is the bridge between the customer or client expectations and employee behaviors.

Response 4-HRD embodies the leadership brand. HRD professionals have the responsibility to produce the next generation of leaders by helping to establish the leadership brand, assessing the gaps in the current leadership against this brand, and then investing in future leaders. They also should embody the brand in what they deliver and how they go about delivering it.

Challenge 5-Learning: An organization needs to be good at generating and generalizing ideas with impact. Generating new ideas comes from benchmarking (seeing what 
others have done and adapting it), experimentation (trying new things to see if and how they work), competence acquisition (hiring or developing people with new skills and ideas), and continuous improvement (improving on what was done through suggestion systems and process analysis). Generalizing ideas means that the ideas move across a boundary of time (from one leader to the next), space (from one geography to another), or division (from one business unit to another). Sharing ideas across boundaries may be done through leveraging, technology, creating communities of practice, or moving people.

Response 5-HRD learns. HRD professionals make learning happen by designing and tailoring training, work experience, and life experiences for key individuals throughout the company. They also must embody a learning mentality and become learning mentors by constant inquiry about how they can improve and upgrade their own work.

Challenge 6-Collaboration: An organization needs to be good at working across boundaries to ensure both efficiency and leverage. The whole needs to be greater than the sum of the parts. Some organizations have more value broken up than held together. These organizations do not understand collaboration as a capability. Collaboration may come when the combined organization gains efficiencies of operation through shared services, technology, or economies of scale. Collaboration may also come when the combined organization accomplishes more together than it could separately through learning and sharing ideas across boundaries, allocating resources to key areas, and creating strategies that leverage products and customers.

Response 6-HRD collaborators. HRD professionals build collaboration by seeking both efficiencies and leverage throughout the organization and beyond. In training programs, this might mean bringing in cross-company teams or in job reassignments that move individuals across organization boundaries. It means developing modules on collaborative behavior and then following up with the material taught to ensure its application.

Challenge 7-Talent: An organization reflects the competence and commitment of the employees inside the company. Ensuring talent means going beyond the platitudes that "people are our most important asset" and "strategy follows people" and investing time and resources to securing superior talent. Employees must be both competent and committed. Competent employees have the skills for today's and tomorrow's business requirements. Committed employees deploy those skills regularly and predictably.

Response 7-HRD arbitrates and guarantees talent. HRD professionals may assess the extent to which their organization regularly attracts and keeps top talent and the extent to which that talent is productive and focused. Ensuring competent employees comes as organizations buy (bring in new talent), build (develop existing talent), borrow (access thought leaders through alliances or partnerships), 
bounce (remove poor talent), and bind (keep the best talent). They also may help ensure that the talent inside the company is engaged or committed by helping craft an employee value proposition, or a statement of what employees get from their contribution to their organization.

Challenge 8-Customer connection: An organization needs to be good at building enduring relationships of trust with targeted customers. Many firms have discovered through customer value analysis that 20 percent of customers account for 80 percent of business performance. These target customers and clients become absolutely critical for a firm to compete and succeed. Creating customer connectivity may originate in a variety of practices. It may originate in databases that identify and track individual customer preferences. Customer connectivity may also come from dedicated account teams who build long-term relationships with targeted accounts and clients.

Response 8-HRD connects with targeted customers. Customer connection may come from involving a customer or client in the firm's HRD practices. To leverage such opportunities, many firms are including customers in design, delivery, or attendance at training events. And all HRD activities can have a customer flair by ensuring that customer and client ideas and needs are central to what is being delivered.

Challenge 9-Innovation: An organization needs to be good at doing something new in both content and process. Innovation focuses on share of opportunity by creating the future rather than relying on past successes. Innovation matters because it fosters growth. It excites employees by focusing on what can be, anticipates customer requests, delights customers with what they did not expect, and builds confidence with investors and funders by creating intangible value.

Response 9-HRD as innovators. HRD professionals who focus on innovation constantly ask, What's next? in all domains of their HRD work. Innovative product offerings include courses, workshops, and experiences. Innovation may occur in the delivery of HRD activities through technology-based learning or focused groups.

Challenge 10-Efficiency: An organization needs to be good at managing costs of operation. In competitive and complex markets, managing costs efficiently increases flexibility.

Response 10-HRD as manager of costs. HRD professionals may reduce costs through process, people, and projects. Process improvements reduce variance, remove steps in doing HRD work, reduce program offerings, and ensure a flow of HRD products and services. People improvements come from doing more with less through technology, teams, and more efficient processes. Project investments come from managing capital spending for HRD activities to allocate money wisely for future investments. 


\section{Conclusion}

We end where we began. The world is changing. It requires that HRD professionals contribute by creating value. This value is created when HRD professionals master the ten proposed principles and can turn that knowledge into a set of HRD activities. HRD professionals are better able to do this value-added work when the function is accurately structured and when they act, play roles, and demonstrate the right competencies.

This road map is a daytime dream for HRD. It lays out where HRD can and should be headed. And as a nighttime dream, it lays out challenges ahead and how HRD can respond to those challenges. Night dreams that alert us to our deeper and hidden concerns can be turned into successful daytime dreams by taking the actions I have suggested.

DAVE UlRich

EDITOR

Dave Ulrich is professor in the Ross School of Business at the University of Michigan and a partner with the RBL Group. 